\title{
Investigating the Physical Properties of Sintered Alumina in the Presence of MgO Nanopowder
}

\author{
Mehran Dadkhah, Abdollah Saboori, and Majid Jafari \\ Department of Materials Engineering, Islamic Azad University, Najaf Abad Branch, Isfahan, Iran \\ Correspondence should be addressed to Abdollah Saboori; saboori1985@yahoo.com
}

Received 19 November 2013; Revised 28 January 2014; Accepted 29 January 2014; Published 5 March 2014

Academic Editor: Roger Narayan

Copyright (C) 2014 Mehran Dadkhah et al. This is an open access article distributed under the Creative Commons Attribution License, which permits unrestricted use, distribution, and reproduction in any medium, provided the original work is properly cited.

\begin{abstract}
Magnesium oxide nanopowder is synthesized using magnesium nitrate hexahydrate and oxalic acid as precursors via the sol-gel method. In order to investigate the effect of magnesia nanopowders on the physical properties of sintered alumina, $0.1,0.3$, and $0.5 \mathrm{wt} \%$ of $\mathrm{MgO}$ are added to alumina. The prepared specimens were sintered at $1570^{\circ} \mathrm{C}$ for 4 hours under an inert atmosphere. The morphology and size of nanopowders were characterized by transmission electron microscope (TEM) and scanning electron microscope (SEM). Structural analysis was investigated by means of Fourier transform infrared spectroscopy (FT-IR) and X-ray diffraction (XRD). Outcomes show that by increasing the percentage of $\mathrm{MgO}$, spinel phase $\left(\mathrm{MgAl}_{2} \mathrm{O}_{4}\right)$ has been formed in the structure of alumina. During the sintering process, spinel phase diffused through the grain boundaries and pinned the grain boundaries which led to decrease in grain sizes. So, by decreasing the grain size, the physical properties of sintered alumina have improved.
\end{abstract}

\section{Introduction}

$\alpha-\mathrm{Al}_{2} \mathrm{O}_{3}$ has the highest hardness and density among aluminum oxides that is formed by heating of other polymorphs of alumina or alumina hydrate at a high temperature. Additionally, $\alpha$-alumina can be produced by melting process of alumina hydrate at up to more than $2000^{\circ} \mathrm{C}$ and subsequently its cooling and crushing [1]. Regarding formation of particulate or whisker-reinforced composites with good thermomechanical properties, alumina is compatible with other ceramics such as $\mathrm{ZrO}_{2}$, mullite, cordierite, $\mathrm{SiC}, \mathrm{B}_{4} \mathrm{C}$, and $\mathrm{Si}_{3} \mathrm{~N}_{4}$. Due to the above versatility of its nature, alumina and its composites include more than $70 \%$ of structural ceramics [2]. Another reason alumina is significant compared to other engineering oxide ceramics is due to a lower sintering temperature which makes it economical. In recent years, nanomaterials attract more attention in comparison with micron size materials due to a high surface area which leads to its specific properties. For instance, particles with nanodimension can increase strength, ductility, and formation of ceramics. Moreover, nanoparticles are used for producing transparent coats. Nanoalumina powders are also applied to the production of ceramic parts with hardness and wear resistance as well as raw materials in the catalyst industry $[3,4]$. Furthermore, alumina nanosize with regard to micron size alumina can reach a higher density at lower temperature; hence it is utilized as a raw material in the generation of alumina ceramic bodies. There are different methods to synthesize nanomaterials including mechanical alloying [5], vapor phase reaction route [6], precipitation [7], sol-gel [8], and combustion [9]. The mechanical alloying route takes too long and also during this process the final powders can be polluted. In vapor phase methods there are some disadvantages such as high cost equipment and low efficiency. Among these methods, sol-gel is a simple and economical route with high efficiency and specific properties at low temperature like high surface area in volume ratio, fine particle size distribution, and so on [10].

Among the oxide compounds, magnesium oxide ( $\mathrm{MgO})$ has interesting properties and is employed in industrial applications [11-20]. In 1961, Coble investigated the effect of a small amount of magnesia on sintering of alumina for the first time and they reported that the adding of $\mathrm{MgO}$ less than $0.25 \mathrm{wt} \%$ led to obtaining a density near the theoretical 


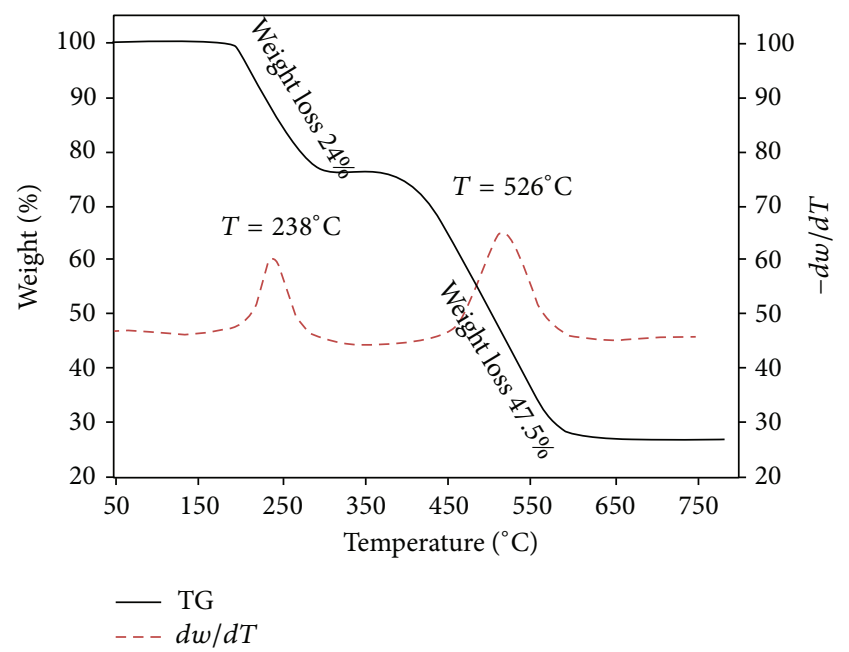

FIgURE 1: The differential thermal analysis (DTA) of dried sol-gel product at $100^{\circ} \mathrm{C}$ for $24 \mathrm{hrs}$ [22].

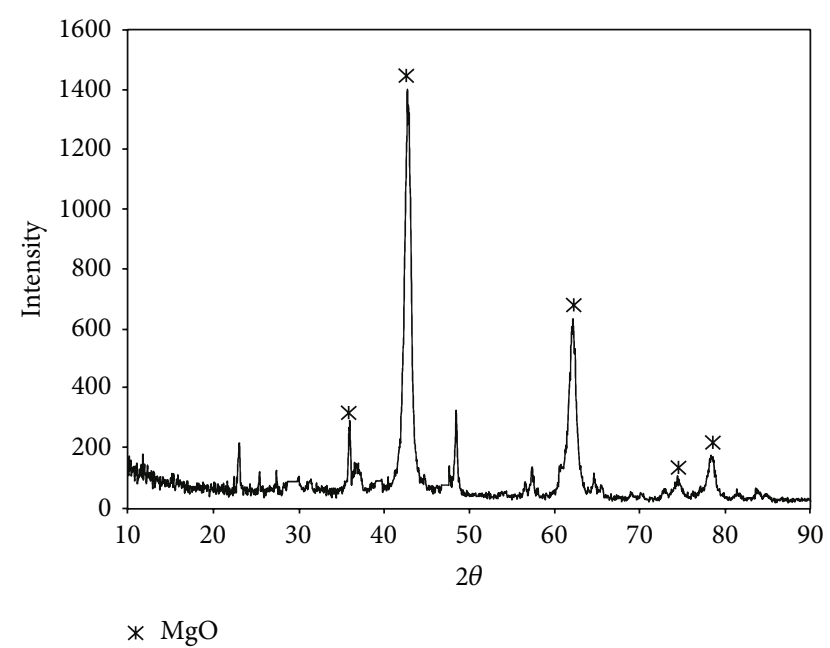

Figure 2: X-ray diffraction of pattern of a calcined specimen at $600^{\circ} \mathrm{C}$.

value [21]. The present study has focused on the synthesis of nanopowder via sol-gel method by magnesium nitrate and oxalic acid as a precursor and investigating the effect of synthesized $\mathrm{MgO}$ powder on the wear property of alumina.

\section{Materials and Methods}

The magnesia $(\mathrm{MgO})$ nanopowder used in the present study is prepared according to a sol-gel method by use of $\left[\left(\mathrm{Mg}\left(\mathrm{NO}_{3}\right)_{2} \cdot 6 \mathrm{H}_{2} \mathrm{O}\right)\right.$ (Merck, 99\%)] and oxalic acid $\left[(\mathrm{COOH})_{2} \cdot 2 \mathrm{H}_{2} \mathrm{O},(\right.$ Merck, $\left.99 \%)\right]$ as precursors in 1:1 molar ratio [22]. In the first step, the starting materials are dissolved in ethanol separately to acquire clear solutions. Subsequently, these two solutions are mixed together to achieve a thick white gel. The white gel is aged for 12 hours and then dried at $100^{\circ} \mathrm{C}$ for 24 hours. In the next step, the product is ground, sieved, and calcinated at $600^{\circ} \mathrm{C}$ for 2 hours and

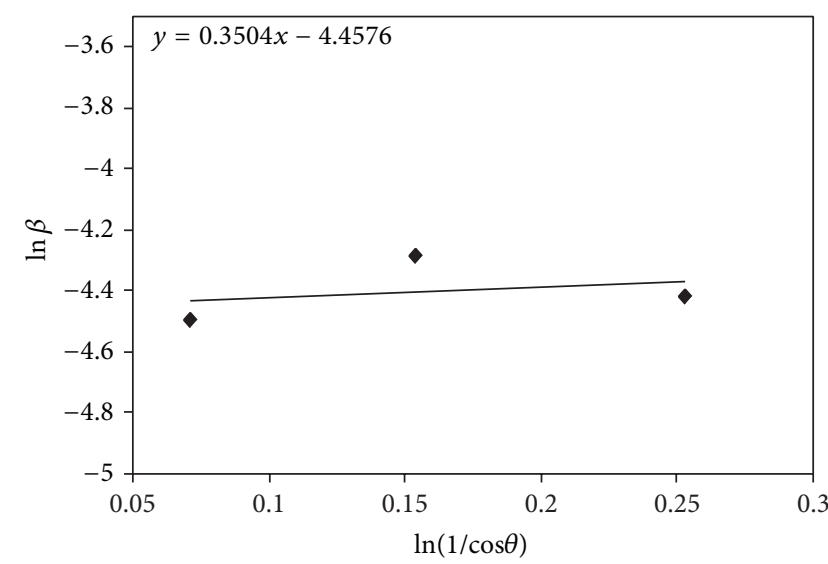

Figure 3: Calcined $\mathrm{MgO}$ at $600^{\circ} \mathrm{C}$.

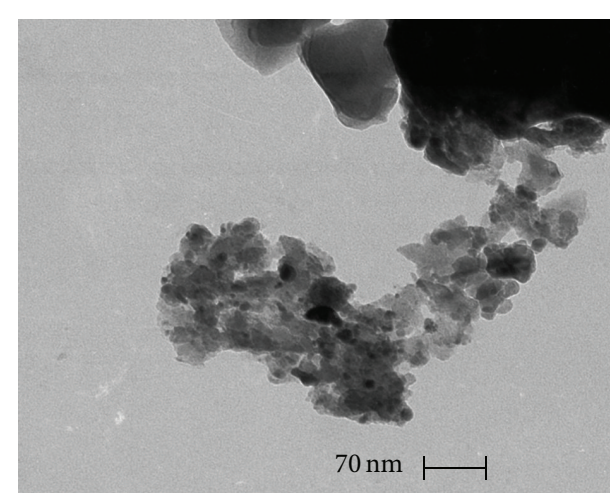

FIgUre 4: The TEM image of calcined sample at $600^{\circ} \mathrm{C}$.

cooled at a rate of $10^{\circ} \mathrm{C} / \mathrm{min}$. To examine the effect of synthesized $\mathrm{MgO}$ nanopowder on the physical properties of alumina, $0.1,0.3$, and $0.5 \mathrm{wt} \% \mathrm{MgO}$ are added to alumina powder (Commercial alumina, Alcan France, Micron size) and the samples are formed by cold isostatic press. The diameter of samples for sintering runs is typically $10 \mathrm{~mm}$ in diameter. The average relative green density is $68 \%$ for alumina. After completing the setting, the green samples are left in a standard electrical furnace at $1570^{\circ} \mathrm{C}$ with 4 hours soaking time for pure alumina and magnesia-doped alumina. For a more precise investigation, at least two samples are sintered at the same temperatures. In order to increase the sintering rate, inert atmosphere is applied. Examining the influence of $\mathrm{MgO}$ nanopowders on the physical properties of alumina has been done by measuring the wear and density of samples after sintering. The density of the samples is measured by Archimedes' method by employing distilled water for the immersion media. Then, the relative density $(D)$ is obtained by using a theoretical volume mass of $3.976 \mathrm{gcm}^{-3}$ for alumina (calculated from the elemental lattice structure of the $\alpha$-alumina phase). Apart from the study on the formation of $\mathrm{MgO}$ and its stability, thermal analysis of the dried product is performed with a computer-controlled thermogravimetric analysis (TGA) [22]. For the identification of phase(s) and determining the average crystallite size, X-ray 
TABLE 1: Calculations for measuring the nanocrystallite size of $\mathrm{MgO}$ according to modified Scherrer equation.

\begin{tabular}{lcccccccccc}
\hline $\operatorname{Ln}(1 / \cos \theta)$ & $1 / \cos \theta$ & $\operatorname{Ln} \beta$ & $\sin \theta$ & $\beta \cos \theta$ & $\cos \theta$ & $\theta(\mathrm{Rad})$ & $\theta(\mathrm{Deg})$ & $2 \theta$ & $\beta(\mathrm{Rad})$ & $\beta(\mathrm{Deg})$ \\
\hline 0.071 & 1.074 & -4.496 & 0.365 & 0.010 & 0.931 & 0.373 & 21.458 & 42.916 & 0.011 & 0.640 \\
0.154 & 1.166 & -4.288 & 0.515 & 0.012 & 0.857 & 0.541 & 31.086 & 62.172 & 0.014 & 0.787 \\
0.253 & 1.288 & -4.422 & 0.630 & 0.009 & 0.777 & 0.682 & 39.194 & 78.388 & 0.012 & 0.689 \\
\hline
\end{tabular}

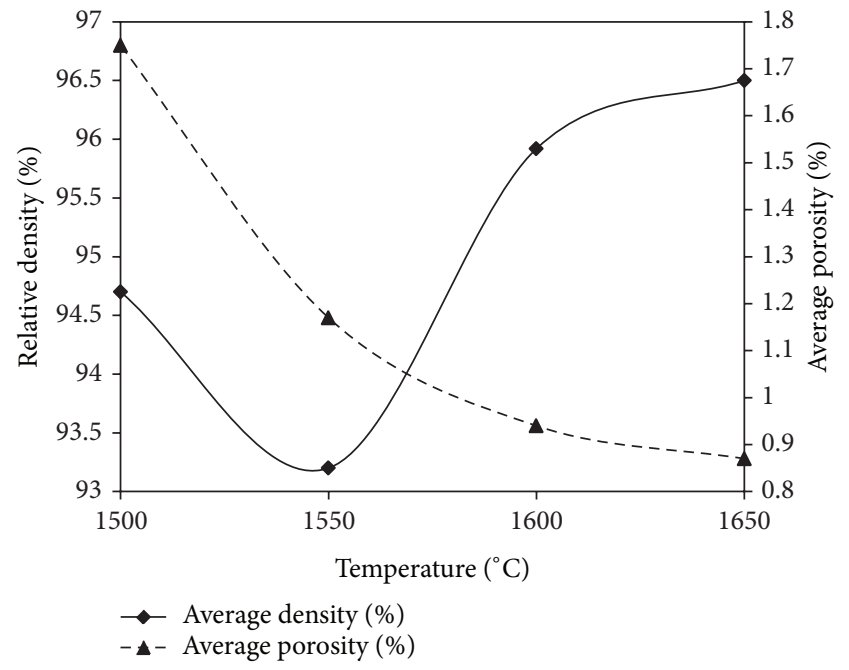

FIGURE 5: Change in percentage of relative density and average porosity of sintered $\mathrm{Al}_{2} \mathrm{O}_{3}-0.1 \% \mathrm{MgO}$ samples in the range of $1500-$ $1650^{\circ} \mathrm{C}$.

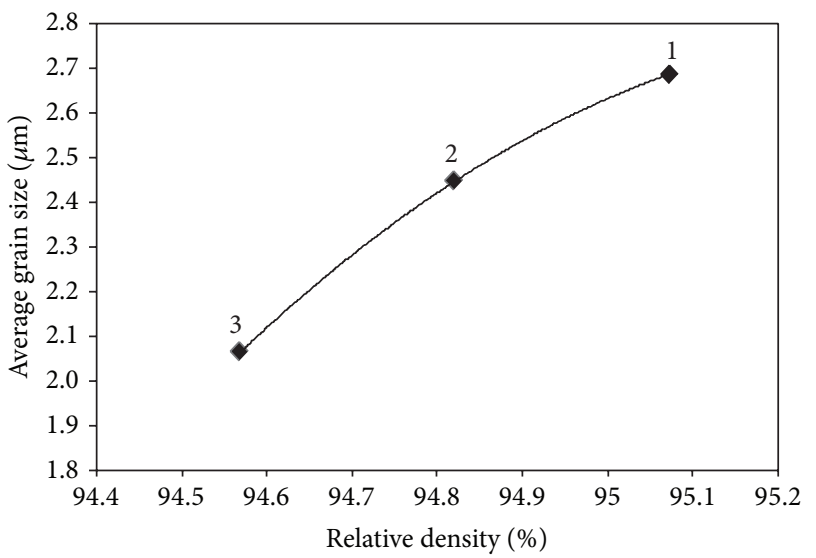

(1) $\mathrm{Al}_{2} \mathrm{O}_{3}$ (micron)

(2) $\mathrm{Al}_{2} \mathrm{O}_{3}$ (micron) $-0.1 \% \mathrm{MgO}$

(3) $\mathrm{Al}_{2} \mathrm{O}_{3}$ (micron) $-0.5 \% \mathrm{MgO}$

Figure 6: Percentage changes of relative density with average grain size.

powder diffractometer with Philips, $\lambda=1.5404 \AA$ is used. Additionally, scanning electron microscopes (SEM Seron tech and Vega, TEM Philips CM10) are utilized for observing the morphology and microstructure development of the sintered specimens. Microstructures of sintered samples are characterized by observing fracture surfaces that are thermally etched for 30 minutes (etching is performed at $300^{\circ} \mathrm{C}$ below the sintering temperature). The average grain size, $\mathrm{G}$, is determined from the SEM micrographs employing line intercept method [23]. A three-dimensional correction factor of 1.2 is used, meaning individual grains are approximated by spheres.

\section{Results and Discussion}

\subsection{Magnesia Nanopowder}

3.1.1. Thermal Analysis of Synthesized Nano-MgO. The thermal behavior of the dried product was investigated by raising its temperature up to $800^{\circ} \mathrm{C}$ at the rate of $4^{\circ} \mathrm{C} / \mathrm{min}$. According to differential thermal analysis (DTA), two main levels of weight loss are seen in Figure 1 [22]. In the first stage, at a temperature in the range of $201-282^{\circ} \mathrm{C}$, a weight loss of about $24 \%$ is observed which is attributed to the removal of crystal water of $\mathrm{MgC}_{2} \mathrm{O}_{4} \cdot 2 \mathrm{H}_{2} \mathrm{O}$. In the second stage, another weight loss of about $47.5 \%$ has been seen between $416-564^{\circ} \mathrm{C}$ which is ascribed to the decomposition of $\mathrm{MgC}_{2} \mathrm{O}_{4}$ and the formation of magnesia nanopowders. Residual materials are indicated as weight loss $\sim 1 \%$ at the temperature of up to $564^{\circ} \mathrm{C}$ [22]. With attention to the results, the decomposition temperature of dried gel powder and formation of $\mathrm{MgO}$ are arranged in the range of $500-1000^{\circ} \mathrm{C}$.

3.1.2. Phase Analysis and Microstructure Evolution. Particle size and phase analysis of nanomaterials are characterized by $\mathrm{X}$-ray diffraction. The X-ray diffraction (XRD) pattern of a calcined specimen at $600^{\circ} \mathrm{C}$ is shown in Figure 2. According to this pattern, it is clear that there are some peaks in the range of $10^{\circ}-80^{\circ}$ (to $2 \theta$ ) that are in good agreement with the standard pattern of periclase. Generally, in the XRD pattern, particle size vigorously depends on the intensity and angle of the maximum peak. In the Scherrer equation $(L=$ $k \lambda / \beta \cos \theta)$, nanocrystallite size is calculated by full-width at half-maximum of peak $(\beta)$ and XRD radiation of wavelength $\lambda \mathrm{nm}$. However, if the value of $L$ is the same for all of the peaks of a pattern, $\beta \cos \theta$ should be equal. Therefore, for a typical $5 \mathrm{~nm}$ crystallite size and $\lambda_{\mathrm{CuK} \alpha 1}=0.15405 \mathrm{~nm}$ the peak at $2 \theta=170^{\circ}$ must be more than ten times wider with respect to the peak at $2 \theta=10^{\circ}$, which is never observed. Thus, the present study has used modified Scherrer equation to estimate more accurately nanocrystallite size using XRD which was presented by Monshi et al. [24]. The modified Scherrer equation plots $\ln \beta$ against $\ln (1 / \cos \theta)$ and obtains the intercept of a least squares line regression, $\ln =K \lambda / L$, from which a single value of $L$ is obtained through all of the available peaks.

As can be viewed in Figure 2, most of the peaks are matched with a mineral material that is called magnesium 


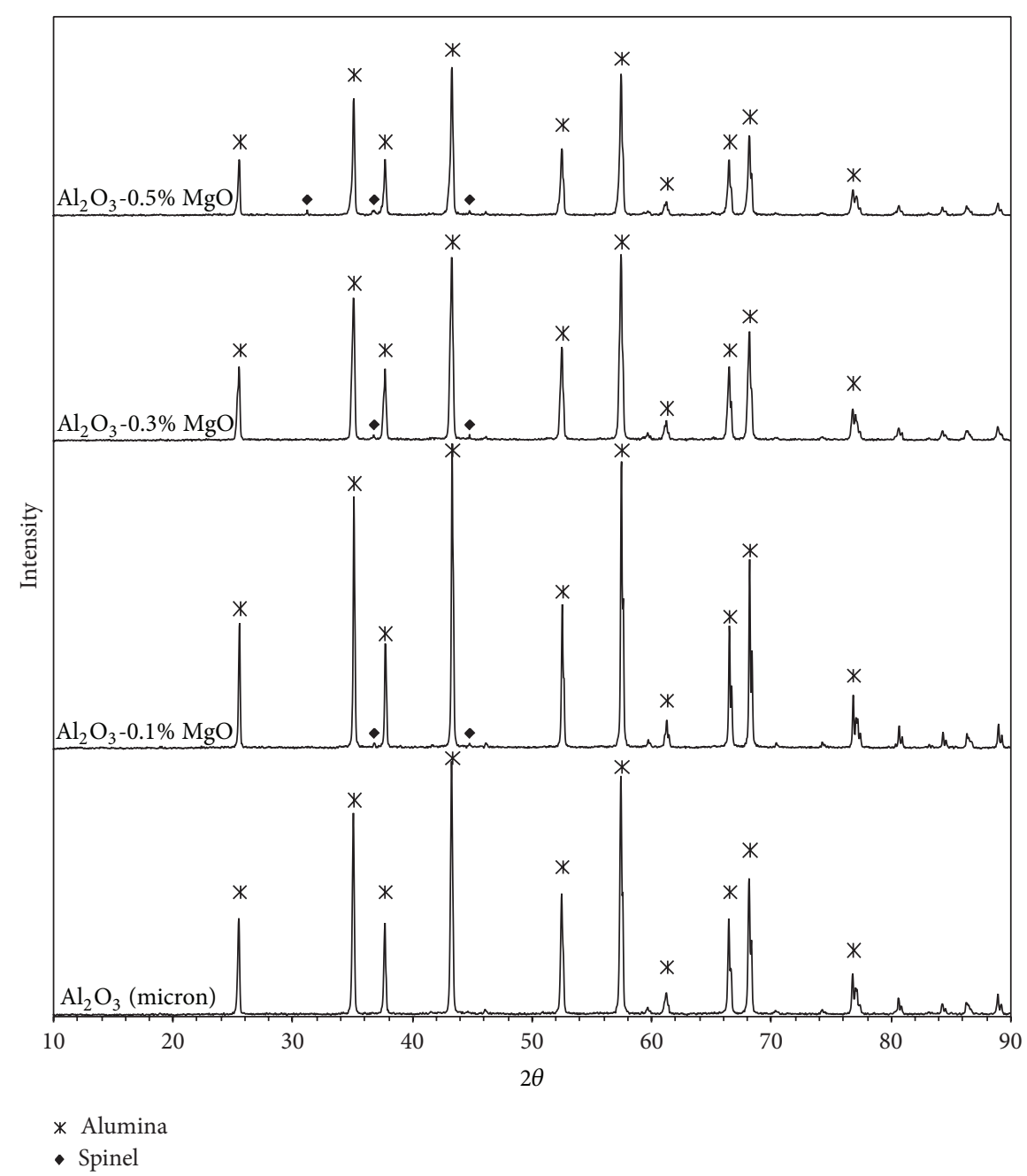

FIGURE 7: XRD pattern of sintered alumina samples with various percentages of nanomagnesia.

oxide with the chemical formula $\mathrm{MgO}$, a cubic crystallography structure, and a space group F23 with group space number 196, the lattice parameters $a=4.22 \AA$, and angles $\alpha=\beta=\gamma=90^{\circ}$. The XRD pattern agrees fairly well with the TG diagram. In the TG diagram, the decomposition of magnesium oxalate is at $526^{\circ} \mathrm{C}$, following which $\mathrm{MgO}$ is formed. In order to calculate the nanocrystallite size of $\mathrm{MgO}$, FWHM for three main peaks should be determined and according to the modified Scherrer equation [24] the plot of $\ln \beta$ against $\ln (1 / \cos \theta)$ must be drawn. The calculations for measuring the nanocrystallite size of synthesized $\mathrm{MgO}$ are shown in Table 1 . The crystal size of synthesized MgO according to this plot is calculated at about $15 \mathrm{~nm}$. The plot of $\ln \beta$ against $\ln (1 / \cos \theta)$ is illustrated in Figure 3 .

The crystal size of synthesized $\mathrm{MgO}$ was also assessed by Transmission electron microscope along with the modified Scherer method and the TEM image (Figure 4) verify the calculations.

Figure 4 shows the image of transmission electron microscopy of calcined magnesia powder at $600^{\circ} \mathrm{C}$. It is noticeable that magnesia nanopowders with a size of less than $70 \mathrm{~nm}$ have been formed as agglomerates.
3.2. Investigating the Physical Properties of Alumina Samples after Sintering. As can be observed in Figure 5, the average percentage of relative density for samples in the range of $1500-1650^{\circ} \mathrm{C}$ is fluctuational. With the increase in temperature from $1500^{\circ} \mathrm{C}$ to $1550^{\circ} \mathrm{C}$, the average percentage of relative density has declined from $94.7 \%$ to $93.2 \%$. On the contrary, by raising the temperature from $1550^{\circ} \mathrm{C}$ to $1650^{\circ} \mathrm{C}$ it has resulted in decreasing the amount of porosity and obtaining a denser body. Although these changes in the percentage of relative density can be attributed to percentage of porosity, it is clear that there is a relation between the temperature and relative density in such a way that at the temperatures below $1550^{\circ} \mathrm{C}$ the diffusion process cannot be completed, so after $1550^{\circ} \mathrm{C}$ by increasing the temperature the density will increase while below this temperature the story is different.

To survey the effect of amount of nanomagnesia on the physical properties of alumina, the specimens with various percentages of $\mathrm{MgO}(x=0,0.1,0.3,0.5 \mathrm{wt} \%)$ were sintered at $1570^{\circ} \mathrm{C}$ for 4 hours which is close to the industrial condition for sintering of alumina. Figure 6 indicates the changes in percentage of relative density with particle size of samples with different $\mathrm{MgO}$. It is evident that these two parameters 


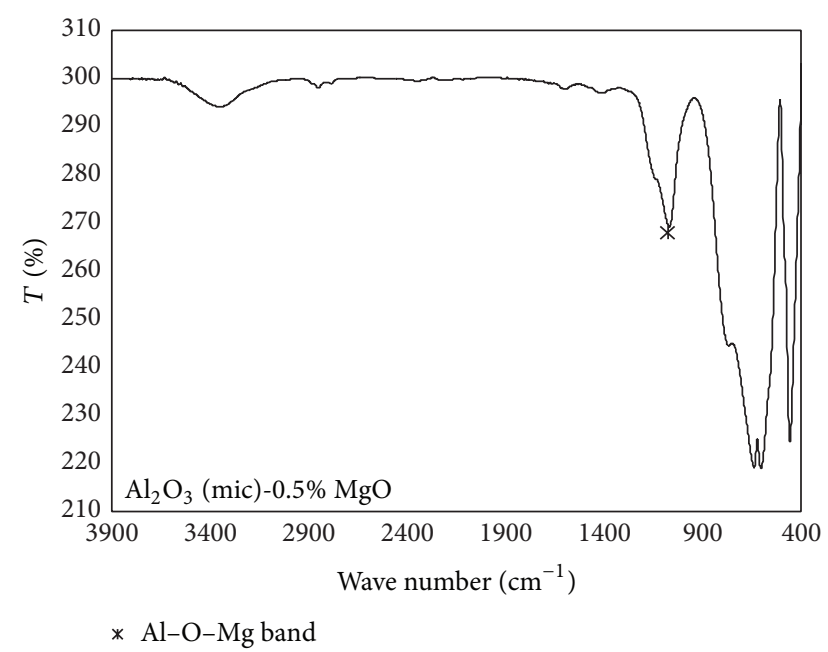

FIGURE 8: FT-IR analysis of $\mathrm{Al}_{2} \mathrm{O}_{3}-0.5 \% \mathrm{MgO}$ after sintering at $1570^{\circ} \mathrm{C}$ for $4 \mathrm{hrs}$.

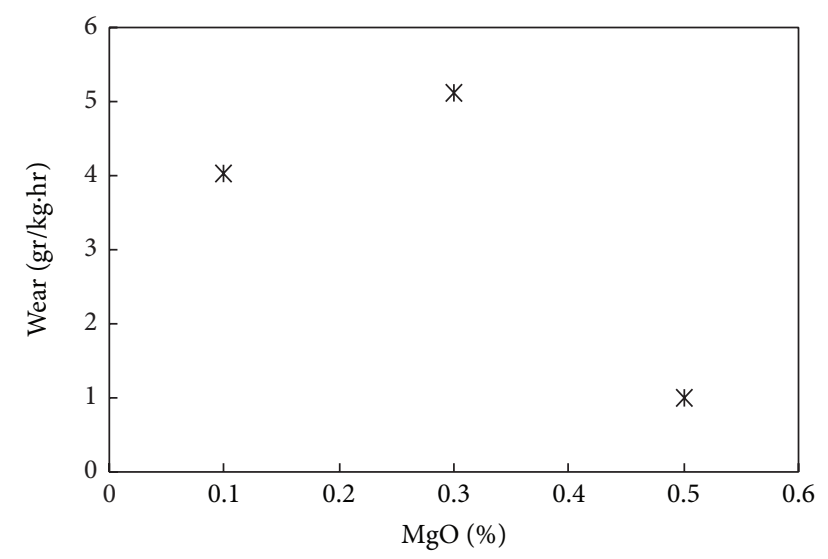

FIGURE 9: Wear changes of sintered alumina samples with $\mathrm{MgO}$ weight percent.

have a converse correlation with each other. However, the comparison between diagrams 5 and 6 finds that, by raising the percentage of magnesia, the particles sizes decreased which leads to an increase in the density of specimens.

Research findings about the effect of additives to alumina indicate that a rise in the amount of $\mathrm{MgO}$ can lead to increased density of sintered samples and control of grain growth. Magnesium ions diffuse in grain boundaries and pin them. MgO with creation vacancies increase $D_{\mathrm{L}}$ and $D_{\mathrm{b}}$ (lattice diffusion coefficient and grain boundary diffusion coefficient) and subsequently raise the rate of grain boundary diffusion which leads to an increased densification. Additionally, due to the relation between porosity and grain boundary, abnormal grain growth is prevented [25]. Furthermore, an increase in density is attributed to the formation of a second phase which is called spinel with chemical formula $\left(\mathrm{MgAl}_{2} \mathrm{O}_{4}\right)$. By diffusion of the spinel phase in grain boundaries, the grain growth has been suppressed, so by raising the $\mathrm{MgO}$ percentage, the grain growth is prevented and finally the grain size will be decreased. X-ray diffraction and FT-IR of sintered samples verified the formation of spinel phase in samples. The XRD pattern of samples after sintering at $1570^{\circ} \mathrm{C}$ for 4 hours is shown in Figure 7 . As can be observed, by increasing the nano- $\mathrm{MgO}$ percentage the intensity of peaks declines and the peaks which are related to formation of spinel are clearer. In the alumina specimens with $0.1 \mathrm{wt} \%$ and $0.5 \mathrm{wt} \%$ nano- $\mathrm{MgO}$, the numbers of peaks which are related to spinel are two and three, respectively.

Figure 8 shows the FT-IR of sintered samples with $0.5 \mathrm{wt} \% \mathrm{MgO}$. As can be seen, the peak that appeared in $1097 \mathrm{~cm}^{-1}$ is related to Al-O-Mg bond. In accordance with the standard, peaks of $\mathrm{Al}-\mathrm{O}$ bond in 520, 690, 914, 1379, $1633 \mathrm{~cm}^{-1}$ and peaks of $\mathrm{Mg}-\mathrm{O}$ bond in 435, 541, 851, 1090, 1400 , and $1500 \mathrm{~cm}^{-1}$ appear.

The wear changes of sintered alumina specimens against nano- $\mathrm{MgO} \%$ are illustrated in Figure 9. As can be detected, by increasing the percentage of magnesia up to $0.3 \mathrm{wt} \%$ the wear of alumina samples increased; then by raising the $\mathrm{MgO}$ percentage to $0.5 \mathrm{wt} \%$, this property is decreased up to five fold.

SEM images of sintered alumina samples with different $\mathrm{MgO}$ wt $\%$ at $1570^{\circ} \mathrm{C}$ for 4 hours under an inert atmosphere are shown in Figure 10. As can be observed, $\mathrm{Al}_{2} \mathrm{O}_{3}$ 0.1 wt $\% \mathrm{MgO}$ specimens with particle size of $\sim 2.6 \mu \mathrm{m}$ in comparison with other percentages of $\mathrm{MgO}$ indicate bigger particle size (Figure 10(a)). While, by raising $\mathrm{MgO}$ to 0.3 and $0.5 \mathrm{wt} \%$, the particle size of specimens is decreased to $2.4 \mu \mathrm{m}$ (Figure 10(b)) and $2 \mu \mathrm{m}$ (Figure 10(c)), respectively.

By investigating sintering mechanism in alumina samples and the effect of additives on this process, it is found that pinning the grain boundaries is the simplest way for control of grain growth. In total, kinetic grain growth is controlled by the decrease in grain boundary motion which is due to grains pinning power. Fine particles and precipitations that do not dissolve into structure can affect stability of structure up to a high temperature. Due to that, the dissolving of alloying elements is used in order to delay grain growth. These elements with aggregation in grain boundaries or formation of second phase lead to a decrease in grain boundary motion. In this study, the presence of $\mathrm{MgO}$ in the alumina structure at $700^{\circ} \mathrm{C}$ causes the formation of spinel phase which remains in alumina body as precipitation. In the following sintering process at elevated temperatures, the presence of spinel in grain boundaries resulted in pinning the grain boundaries. This pining process is a reason for suppressesing the grain growth and also decreasing the grain size in alumina sintered bodies which finally lead to improve the physical properties of sintered Alumina. Figure 11 by applying EDAX analysis approves that the presence of magnesium, aluminum, and oxygen is in good agreement with the formation of spinel phase $\left(\mathrm{MgAl}_{2} \mathrm{O}_{4}\right)$ at grain boundary.

\section{Conclusion}

In the present research, magnesia nanopowders were synthesized via sol-gel method. In order to investigate the effect of $\mathrm{MgO}$ nanopowders on the physical properties of sintered alumina, the alumina specimens with $0.1,0.3$, and $0.5 \mathrm{wt} \%$ of $\mathrm{MgO}$ were prepared by isostatic press as ball 


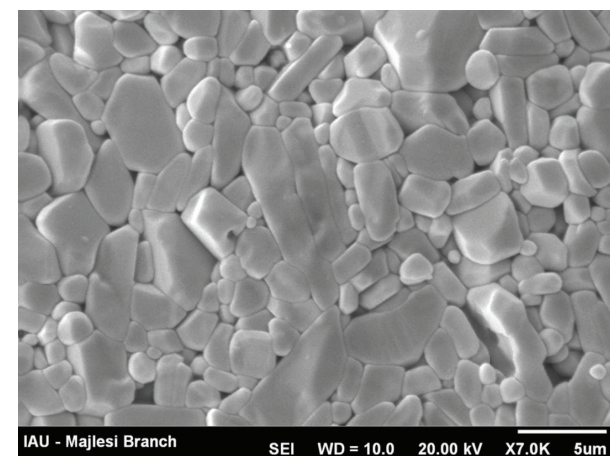

(a)

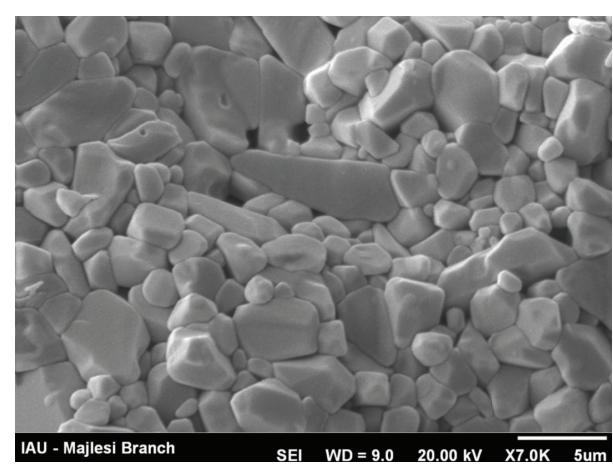

(b)

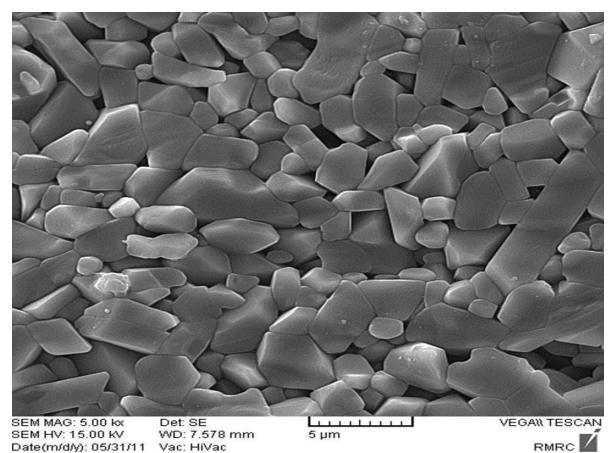

(c)

Figure 10: SEM images of sintered alumina samples at $1570^{\circ} \mathrm{C}$ for $4 \mathrm{hrs}$. (a) $0.1 \mathrm{wt} \% \mathrm{MgO}$, (b) $0.3 \mathrm{wt} \% \mathrm{MgO}$, and (c) $0.5 \mathrm{wt} \% \mathrm{MgO}$.
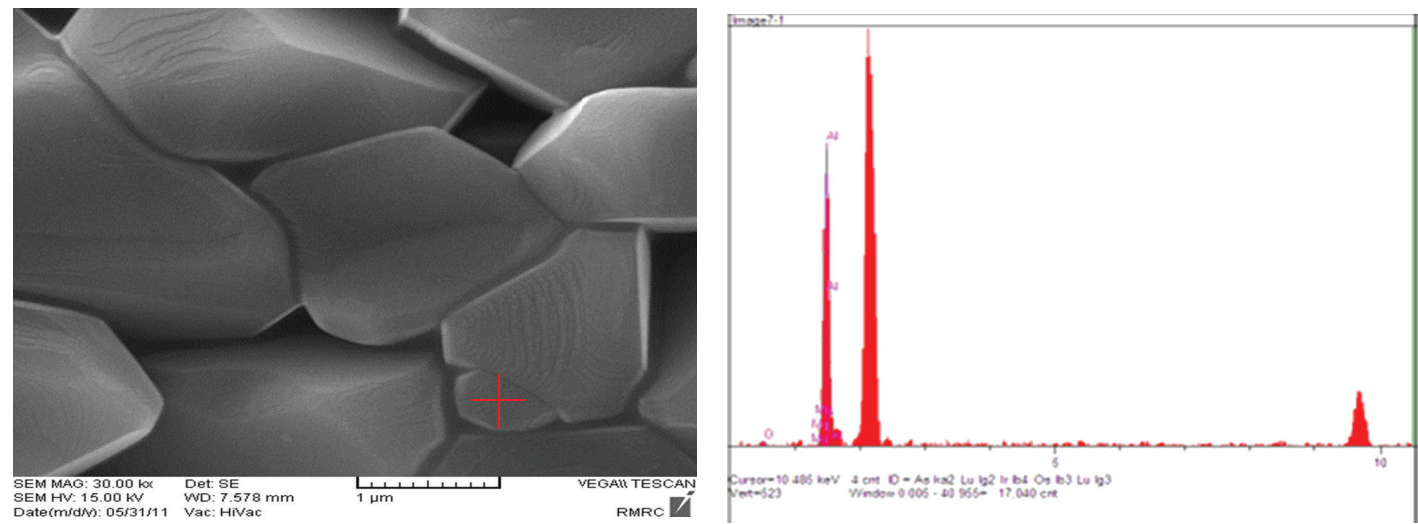

FIgURE 11: EDAX analysis of sintered $\mathrm{Al}_{2} \mathrm{O}_{3}-0.1 \% \mathrm{MgO}$.

and were sintered at $1570^{\circ} \mathrm{C}$ for 4 hours under an inert atmosphere. Effects of $\mathrm{MgO}$ on properties of alumina include the following.

(1) $\mathrm{MgO}$ nanopowders with an average crystal size less than $50 \mathrm{~nm}$ were synthesized via a simple and economical sol-gel method by $\mathrm{Mg}\left(\mathrm{NO}_{3}\right)_{2} \cdot 6 \mathrm{H}_{2} \mathrm{O}$ and $(\mathrm{COOH})_{2} \cdot 2 \mathrm{H}_{2} \mathrm{O}$ as starting materials and ethanol as solvent.

(2) By using the modified Scherrer equation, $\mathrm{MgO}$ with a particle size of $20 \mathrm{~nm}$ was synthesized and it was approved by electric microscope images (SEM, TEM).
(3) In a certain amount of $\mathrm{MgO}$, change in percentage of relative density by increasing the temperature from $1500^{\circ} \mathrm{C}$ to $1650^{\circ} \mathrm{C}$ was not lineal.

(4) At a constant temperature, by raising $\mathrm{MgO} w \mathrm{wt} \%$, the average particle size of alumina has declined.

(5) By decreasing the grain size of alumina samples by $\mathrm{MgO}$ addition, the percentage of relative density of samples has climbed.

(6) At elevated temperatures the magnesia and alumina have formed spinel phase. Spinel phase with diffusion through the grain boundaries leads to the formation of a structure with fine grains. 


\section{Conflict of Interests}

The authors declare that there is no conflict of interests regarding the publication of this paper.

\section{References}

[1] P. K. Panda, V. A. Jaleel, and G. Lefebvre, "Thermal shock study of $\alpha$-alumina doped with $0.2 \% \mathrm{MgO}, "$ Materials Science and Engineering A, vol. 485, no. 1-2, pp. 558-561, 2008.

[2] I. Ganesh, P. M. C. Torres, and J. M. F. Ferreira, "Densification ability of combustion-derived $\mathrm{Al}_{2} \mathrm{O}_{3}$ powders," Ceramics International, vol. 35, no. 3, pp. 1173-1179, 2009.

[3] J. Li, Y. Wu, Y. Pan, W. Liu, Y. Zhu, and J. Guo, "Agglomeration of $\alpha-\mathrm{Al}_{2} \mathrm{O}_{3}$ powders prepared by gel combustion," Ceramics International, vol. 34, no. 6, pp. 1539-1542, 2008.

[4] H. Gleiter, "Nanocrystalline materials," Progress in Materials Science, vol. 33, no. 4, pp. 223-315, 1989.

[5] M. L. Panchula and J. Y. Ying, "Mechanical synthesis of nanocrystalline $\alpha-\mathrm{Al}_{2} \mathrm{O}_{3}$ seeds for enhanced transformation kinetics," Nanostructured Materials, vol. 9, no. 1-8, pp. 161-164, 1997.

[6] K. Kamata, T. Mochizuki, S. Matsumoto, A. Yamada, and K. Miyokawa, "Preparation of submicrometer $\mathrm{Al}_{2} \mathrm{O}_{3}$ powder by gas-phase oxidation of tris (acetylacetonato) aluminum (111)," Journal of the American Ceramic Society, vol. 68, no. 8, pp. C193-C-194, 1985.

[7] J. G. Li and X. D. Sun, "Synthesis and sintering behavior of a nanocrystalline $\alpha$-alumina powder," Acta Materialia, vol. 48, no. 12, pp. 3103-3112, 2000.

[8] W. M. Zeng, L. Gao, and J. K. Guo, "New sol-gel route using inorganic salt for synthesizing $\mathrm{Al}_{2} \mathrm{O}_{3}$ nanopowders," Nanostructured Materials, vol. 10, no. 4, pp. 543-550, 1998.

[9] J. J. Kingsley and K. C. Patil, "A novel combustion process for the synthesis of fine particle $\alpha$-alumina and related oxide materials," Materials Letters, vol. 6, no. 11-12, pp. 427-432, 1988.

[10] S. A. Hassanzadeh-Tabrizi and E. Taheri-Nassaj, "Sol-gel synthesis and characterization of $\mathrm{Al}_{2} \mathrm{O}_{3}-\mathrm{CeO}_{2}$ composite nanopowder," Journal of Alloys and Compounds, vol. 494, no. 1-2, pp. 289-294, 2010.

[11] S. Shen, P. S. Chow, F. Chen, and R. B. Tan, "Submicron particles of SBA-15 modified with $\mathrm{MgO}$ as carriers for controlled drug delivery," Chemical and Pharmaceutical Bulletin, vol. 55, pp. 985-991, 2007.

[12] Z. Zhou, S. Xie, D. Wan et al., "Multidimensional magnesium oxide nanostructures with cone-shaped branching," Solid State Communications, vol. 131, no. 7, pp. 485-488, 2004.

[13] F. Haraguchi, K.-I. Inoue, N. Toshima, S. Kobayashi, and K. Takatoh, "Reduction of the threshold voltages of nematic liquid crystal electrooptical devices by doping inorganic nanoparticles," Japanese Journal of Applied Physics, vol. 46, no. 33-35, pp. L796-L797, 2007.

[14] J. P. Boeuf, "Plasma display panels: physics, recent developments and key issues," Journal of Physics D, vol. 36, no. 6, pp. R53-R79, 2003.

[15] J. Zhang, F. Pan, W. Hao, and T. Wang, "Effect of MgO doping on the luminescent properties of $\mathrm{ZnO}$," Materials Science and Engineering B, vol. 129, no. 1-3, pp. 93-95, 2006.

[16] S. W. Liu, J. Weaver, Z. Yuan et al., "Ferroelectric (Pb,Sr) $\mathrm{TiO}_{3}$ epitaxial thin films on (001) $\mathrm{MgO}$ for room temperature highfrequency tunable microwave elements," Applied Physics Letters, vol. 87, no. 14, Article ID 142905, pp. 1-3, 2005.
[17] J. V. Stark and K. J. Klabunde, "Nanoscale metal oxide particles/clusters as chemical reagents. Adsorption of hydrogen halides, nitric oxide, and sulfur trioxide on magnesium oxide nanocrystals and compared with microcrystals," Chemistry of Materials, vol. 8, no. 8, pp. 1913-1918, 1996.

[18] R. Kakkar, P. N. Kapoor, and K. J. Klabunde, "Theoretical study of the adsorption of formaldehyde on magnesium oxide nanosurfaces: size effects and the role of low-coordinated and defect sites," Journal of Physical Chemistry B, vol. 108, no. 47, pp. 18140-18148, 2004.

[19] L. Qingwen, Y. Hao, C. Yan, Z. Jin, and L. Zhongfan, "A scalable CVD synthesis of high-purity single-walled carbon nanotubes with porous $\mathrm{MgO}$ as support material," Journal of Materials Chemistry, vol. 12, no. 4, pp. 1179-1183, 2002.

[20] Y. Gu, D. Chen, X. Jiao, and F. Liu, " $\mathrm{LiCoO}_{2}-\mathrm{MgO}$ coaxial fibers: co-electrospun fabrication, characterization and electrochemical properties," Journal of Materials Chemistry, vol. 17, no. 18, pp. 1769-1776, 2007.

[21] R. L. Coble, "Sintering crystalline solids. II. experimental test of diffusion models in powder compacts," Journal of Applied Physics, vol. 32, no. 5, pp. 793-799, 1961.

[22] A. Kumar and J. Kumar, "On the synthesis and optical absorption studies of nano-size magnesium oxide powder," Journal of Physics and Chemistry of Solids, vol. 69, no. 11, pp. 2764-2772, 2008.

[23] ASTM E112-96(2004)e2, “ASTM International," West Conshohocken, Pa, USA, 2004.

[24] A. Monshi, M. R. Foroughi, and M. R. Monshi, "Modified scherrer equation to estimate more accurately nano-crystallite size using XRD," World Journal of Nano Science and Engineering, vol. 2, pp. 154-160, 2012.

[25] S.-J. L. Kang, Sintering, Densification, Grain Growth, and Microstructure, 1st edition, 2005. 

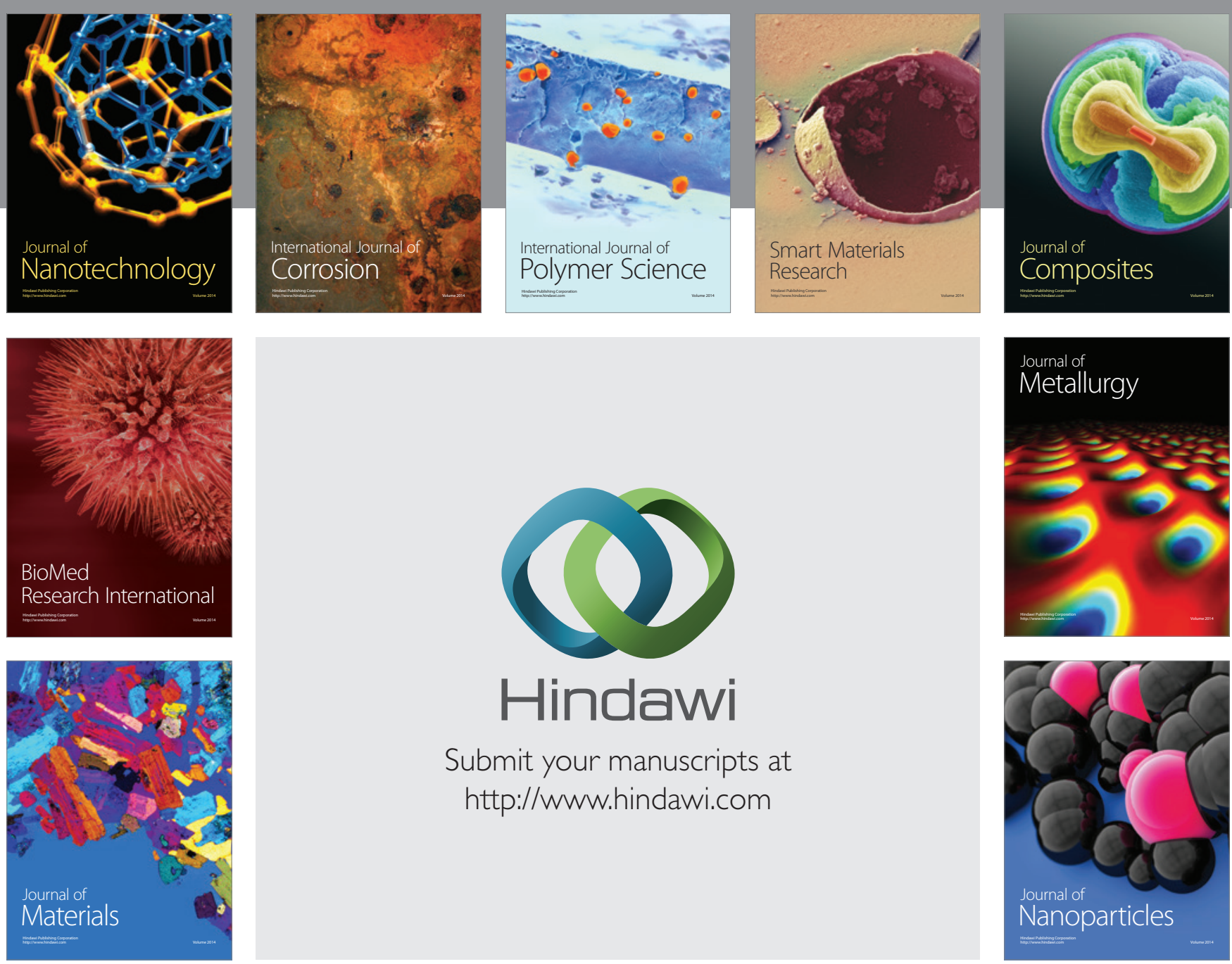

Submit your manuscripts at http://www.hindawi.com
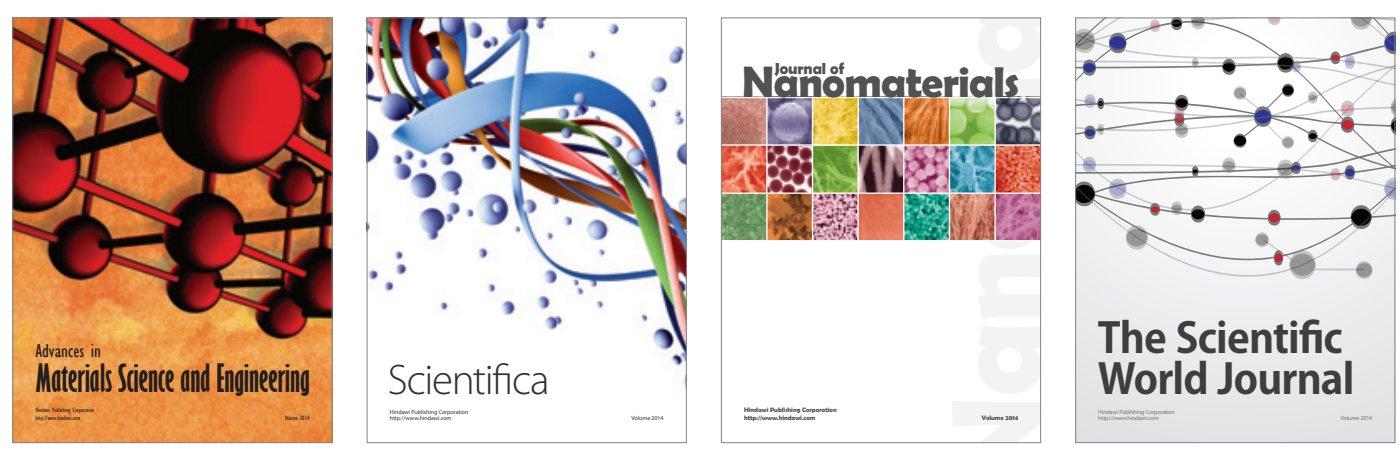

\section{The Scientific World Journal}
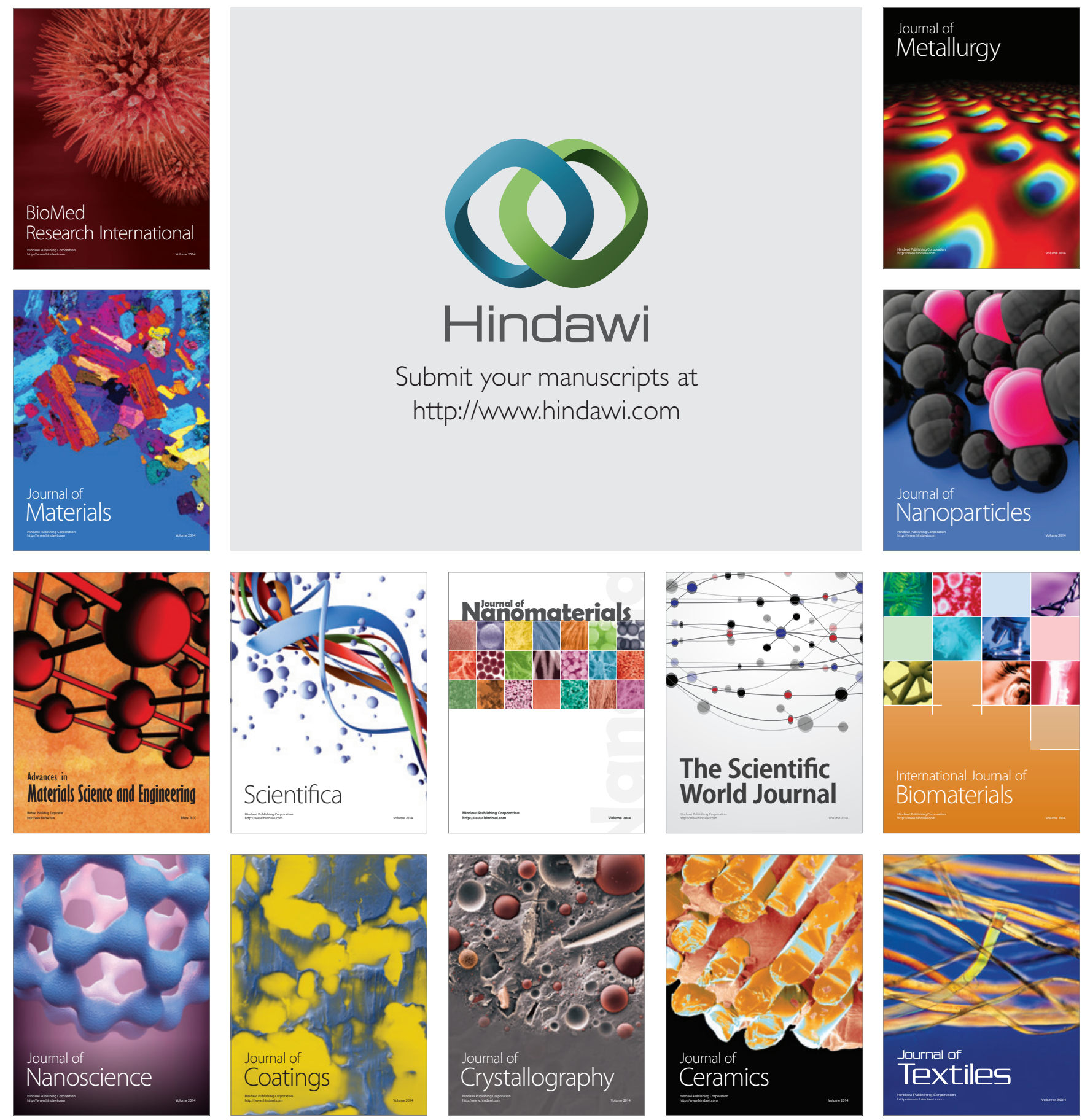